\title{
Differential association of plasma monocyte chemoattractant protein-1 with systemic inflammatory and airway remodeling biomarkers in type-2 diabetic patients with and without asthma
}

Sardar Sindhu', Merin Koshy ${ }^{1}$, Areej Abu Al-Roub ${ }^{1}$, Nadeem Akhter ${ }^{1}$, Saad Al Zanki ${ }^{1}$, Shamsha Ali ${ }^{1}$, Sriraman Devarajan ${ }^{2}$ and Rasheed Ahmad ${ }^{1 *}$

\begin{abstract}
Background: Chronic inflammation is a hallmark of type-2 diabetes (T2D) and asthma. Monocyte chemoattractant protein (MCP)-1 or CCL-2 is a key regulator of monocytic infiltration into the sites of inflammation. The changes in systemic MCP-1 levels and its relationship with other inflammatory/immune markers in T2D patients with asthma remain unclear and have been addressed in this study.

Methods: Plasma samples from 10 asthmatic T2D patients (Group I: BMI $=37.82 \pm 9.75 \mathrm{~kg} / \mathrm{m}^{2}$ ), 13 non-asthmatic T2D patients (Group II: BMI $=32.68 \pm 4.63 \mathrm{~kg} / \mathrm{m}^{2}$ ), 23 asthma patients without T2D (Group III: BMI $=30.14 \pm 6.74 \mathrm{~kg} / \mathrm{m}^{2}$ ), and 25 non-asthmatic non-diabetic controls (Group IV: BMI $=27.99 \pm 5.86 \mathrm{~kg} / \mathrm{m}^{2}$ ) were used to measure levels of MCP1 and multiple cytokine/chemokine biomarkers with bead-based multiplex assays using Luminex technology. IgE/ECP were measured using commercial ELISA kits. Data (mean \pm SEM) were compared using unpaired Student's $t$-test and linear dependence between two variables was assessed by Pearson's correlation coefficient $(r)$ and $P \leq 0.05$ was considered as significant.

Results: Plasma MCP-1 levels were significantly higher in Group I (337.95 \pm 46.40 pg/mL) as compared with Group II $(216.69 \pm 17.30 \mathrm{pg} / \mathrm{mL})$, Group III $(251.76 \pm 19.80 \mathrm{pg} / \mathrm{mL})$, and Group IV $(223.52 \pm 133.36 \mathrm{pg} / \mathrm{mL})$. MCP-1 showed differential association with tested biomarkers by correlating positively with: (i) IFN-a2, IL-10, fractalkine, and VEGF in T2D patients with asthma; (ii) IL-6 and GRO-a in T2D patients without asthma; (iii) MDC, IP-10, GM-CSF, FGF-2, and PDGF-AA/BB in patients with asthma only; and (iv) FPG and TG in non-asthmatic non-diabetic controls. MCP-1 associated with IL-1RA only in subjects with asthma.

Conclusion: The systemic MCP-1 levels were significantly elevated in T2D patients with asthma as compared with those without asthma and/or diabetes while these changes correlated differentially with important biomarkers of inflammation and airway remodeling.
\end{abstract}

Keywords: Type-2 diabetes, Asthma, Monocyte chemoattractant protein-1, Inflammation, Biomarkers

\footnotetext{
* Correspondence: rasheed.ahmad@dasmaninstitute.org

${ }^{1}$ Immunology \& Innovative Cell Therapy Unit, P.O. Box 1180, Dasman 15462,

Kuwait

Full list of author information is available at the end of the article
} 


\section{Background}

The increasing evidence suggests that chronic inflammation is a critical factor involved in type-2 diabetes (T2D) and asthma [1-5]. Monocyte chemoattractant protein (MCP)-1, also known as C-C chemokine ligand (CCL)-2, recruits monocytes to the sites of inflammation, such as into the expanding adipose tissue in obesity/T2D $[6,7]$ or the arterial vessel wall in asthmatic patients [8]. MCP-1, which is associated with a myriad of diseases including allergic asthma, multiple sclerosis, rheumatoid arthritis, atherosclerosis, and insulin-resistant diabetes, is produced by many cell types such as endothelial and epithelial cells, fibroblasts, smooth muscle, mesangial, and microglial cells, however, predominantly by monocytes/macrophages [9].

The lung is also a target organ for diabetic microangiopathy and the reduced lung function has been frequently observed in diabetic patients due to biochemical changes in the connective tissue as well as non-enzymatic glycosylation of proteins induced by chronic hyperglycemia $[10,11]$. Thus, the risk of asthma is elevated in the obese by 2-3 times [12] and in the T2D patients by 2 times [13] as compared with normal subjects. Obesity seems to be the major contributor to the pathogenesis of asthma and the increase in abdominal adiposity negatively impacts the lung volumes and pulmonary and bronchial expansions during inhalation. Notably, obesity and T2D are also characterized by oxidative stress and low-grade chronic inflammation [14]. Since MCP-1 is essentially involved in the pathogenesis of several inflammatory conditions, we hypothesized that it could be a major player of predictive significance and a sensitive biomarker in T2D patients with asthma that are also more likely to develop poor disease prognosis. Therefore, the study objective was to measure the plasma MCP-1 levels and assess their relationship with various inflammatory, airway remodeling, and other immune biomarkers in T2D patients with and without asthma. This study also included non-diabetic asthmatic individuals and non-diabetic non-asthmatic subjects as controls. Herein, we report the significantly higher MCP-1 levels in asthmatic as compared with nonasthmatic T2D pateints. Furthermore, plasma MCP-1 levels associated differentially with inflammatory and lung tissue remodeling biomarkers when compared between asthmatic T2D patients and other study groups.

\section{Methods}

\section{Study population}

This study comprised of 23 diabetic and 48 non-diabetic male/female individuals, further subclassified into 4 groups as follows: Group I including 10 T2D patients with asthma (age $53.60 \pm 7.78$ years; BMI $37.82 \pm 9.75 \mathrm{~kg} / \mathrm{m}^{2}$ ); Group II including $13 \mathrm{~T} 2 \mathrm{D}$ patients without asthma (age $50.92 \pm 6.42$ years; BMI $32.68 \pm 4.63 \mathrm{~kg} / \mathrm{m}^{2}$ ); Group III including 23 asthmatic non-diabetic individuals (age $38.70 \pm 9.34$ years; BMI $30.14 \pm 6.74 \mathrm{~kg} / \mathrm{m}^{2}$ ); and Group IV including 25 non-asthmatic non-diabetic individuals as controls (age $35.96 \pm 8.27$ years; BMI $27.99 \pm 5.86 \mathrm{~kg} / \mathrm{m}^{2}$ ). Written informed consent was obtained from all participants before enrolment in the study and the study protocol was approved by Ethical Review Committee of Dasman Diabetes Institute, Kuwait. Those of age $<18$ years. or $>65$ years. or those suffering from serious cardiovascular, hepatic, or renal disease, hematologic or immune disorder, type-1 diabetes, pregnancy, or malignancy were excluded. Clinical and anthropometric characteristics of study participants are summarized in Table 1.

\section{T2D/asthma diagnosis, anthropometric measurements and biochemical analyses}

T2D diagnosis was based on results of (i) fasting plasma glucose (FPG), (ii) oral glucose tolerance test (OGTT), and (iii) glycated hemoglobin (HbA1c) test. FPG levels of $\geq 126 \mathrm{mg} / \mathrm{dL}$ ( $\geq 7 \mathrm{mmol} / \mathrm{L}$ ), $2 \mathrm{~h}-\mathrm{OGTT}$ values of $>200 \mathrm{mg} /$ $\mathrm{dL}(11.1 \mathrm{mmol} / \mathrm{L})$, and/or HbA1C levels of $\geq 6.5 \%$ on two separate tests were diagnosed by attending physician as T2D. The diagnosis of asthma was based on a compatible clinical history along with an evidence of reversible airflow limitation i.e., increase in forced expiratory volume in $1 \mathrm{~s}$ $\left(\mathrm{FEV}_{1}\right)$ of $\geq 15 \%$ following a bronchodilator or airway hyper-responsiveness i.e., provocative concentration of methacholine causing a $20 \%$ reduction in $\mathrm{FEV}_{1}$. Pulmonary function testing and spirometry were performed according to the standards of the American Thoracic Society [15]. Regarding anthropometric/physical data, height and weight were measured while barefoot, waist circumference was measured and the waist-to-hip ratio was calculated. BMI was calculated as follows: body

Table 1 Characteristics of study population

\begin{tabular}{|c|c|c|c|c|}
\hline \multirow[t]{2}{*}{ Parameter } & \multicolumn{2}{|l|}{ Diabetic } & \multicolumn{2}{|l|}{ Non-diabetic } \\
\hline & Asthmatic & $\begin{array}{l}\text { Non- } \\
\text { asthmatic }\end{array}$ & Asthmatic & $\begin{array}{l}\text { Non- } \\
\text { asthmatic }\end{array}$ \\
\hline Total number (N) & 10 & 13 & 23 & 25 \\
\hline Age (Yrs.) & $53.60 \pm 7.78$ & $50.92 \pm 6.42$ & $38.70 \pm 9.34$ & $35.96 \pm 8.27$ \\
\hline BMI $\left(\mathrm{kg} / \mathrm{m}^{2}\right)$ & $37.82 \pm 9.75$ & $32.68 \pm 4.63$ & $30.14 \pm 6.74$ & $27.99 \pm 5.86$ \\
\hline FPG (mmol/L) & $9.01 \pm 2.57$ & $8.00 \pm 2.57$ & $5.37 \pm 0.60$ & $5.09 \pm 0.65$ \\
\hline HbA1c (\%) & $8.60 \pm 1.25$ & $8.20 \pm 1.85$ & $5.50 \pm 0.42$ & $5.46 \pm 0.49$ \\
\hline $\begin{array}{l}\text { Total cholesterol } \\
\text { (mmol/L) }\end{array}$ & $4.68 \pm 0.44$ & $5.03 \pm 1.00$ & $4.86 \pm 0.86$ & $4.70 \pm 0.62$ \\
\hline $\mathrm{HDL}(\mathrm{mmol} / \mathrm{L})$ & $1.21 \pm 0.32$ & $0.99 \pm 0.25$ & $1.20 \pm 0.31$ & $1.49 \pm 0.73$ \\
\hline LDL (mmol/L) & $2.82 \pm 0.56$ & $3.12 \pm 1.13$ & $3.09 \pm 0.88$ & $2.93 \pm 0.61$ \\
\hline $\mathrm{TG}(\mathrm{mmol} / \mathrm{L})$ & $1.44 \pm 0.72$ & $1.80 \pm 1.21$ & $1.46 \pm 1.65$ & $0.82 \pm 0.45$ \\
\hline
\end{tabular}

$B M I$ body mass index, $\mathrm{HbA1c}$ glycated hemoglobin, FPG fasting plasma glucose, $H D L$ high-density lipoprotein, $L D L$ low-density lipoprotein, $T G$ triglycerides 
weight $(\mathrm{kg}) /$ height $\left(\mathrm{m}^{2}\right)$. An average of the 3 blood pressure readings (Omron HEM-907XL digital automatic sphygmomanometer, Omron Healthcare Inc. IL, USA), taken after 5-10 min rest for each, was obtained. The whole body composition including body fat percentage, soft lean mass and total body water was assessed (IOI 353 Body Composition Analyzer, Jawon Medical, South Korea). Plasma or serum samples were analyzed for FPG, HbA1c, total cholesterol, high- and low-density lipoproteins (HDL, LDL), and triglycerides (TG) levels using standard methods. Briefly, FPG was measured using hexokinase method, HbA1c was measured using Variant device (BioRad, Hercules, CA, USA), serum cholesterol by cholesterol oxidase-peroxidase-amidopyrine method, HDL was measured by direct method using polyethylene glycolpretreated enzymes, LDL was measured using Friedewald formula, and serum triglycerides were measured using glycerol phosphate oxidase-peroxidase-amidopyrine method.

\section{Measurement of plasma analytes}

A wide range of plasma analytes classified as cytokines, chemokines, activation and growth factors were measured using Milliplex MAP human cytokine/chemokine magnetic bead panel-immunology (Cat.\# HCYTOMAG-60 K, Milliplex Corp, USA) multiplex immunoassay while some analytes were measured using commercial enzyme-linked immunosorbent assays (ELISA) such as immunoglobulin (Ig)-E (Human IgE Platinum ELISA kit, Cat.\# BMS2097, eBioscience, Austria), and Eosinophil cationic protein (ECP) (Human ECP kit, Cat.\# SK00128-01, Aviscera Bioscience Inc. CA, USA) and following the manufacturers' instructions. The tested analytes included interferon (IFN)- $\alpha 2$, IFN- $\gamma$, interleukin (IL)- $1 \alpha / \beta$, IL-1 receptor agonist (IL-1RA), IL-2, IL-3, IL-4, IL-5, IL-6, IL-7, IL-8, IL-9, IL-10, IL-12p40/p70, IL-13, IL-15, IL-17A, transforming growth factor (TGF)- $\alpha$, tumor necrosis factor (TNF)- $\alpha / \beta$, macrophage chemoattractant protein (MCP)-1, MCP-3, macrophage inflammatory protein (MIP)- $1 \alpha$ or CCL-3, MIP- $1 \beta / C C L-4$, regulated on activation normal T-cell expressed and secreted (RANTES)/CCL-5, eotaxin/CCL11, macrophage-derived chemokine (MDC)/CCL-22, growth-regulated oncogene (GRO) or CXC chemokine ligand (CXCL)-1, fractalkine/CX3CL-1, IFN- $\gamma$-inducible protein (IP)-10/CXCL-10, epidermal growth factor (EGF), FMS-like tyrosine kinase-3 ligand (FLT-3 L), granulocyte colony-stimulating factor (G-CSF), granulocytemacrophage colony-stimulating factor (GM-CSF), fibroblast growth factor (FGF)-2, platelet-derived growth factor (PDGF)-AA/BB, vascular endothelial growth factor (VEGF), soluble CD40 ligand (sCD40L), ECP, and IgE. Data were acquired using Luminex xMAP analyzer (Luminex 100/200 Milliplex Analyzer, Luminex Corp. USA) following the manufacturer's instructions while a digital processor managed data output and Milliplex analyst software was used to determine mean fluorescence intensity and analyte concentrations $(\mathrm{pg} / \mathrm{mL})$.

\section{Statistical analysis}

For statistical analysis of the data (mean \pm s.e.m.), group means were compared using unpaired Student's $t$-test and linear dependence between two variables was assessed by Pearson's correlation coefficient (r) using GraphPad Prism software (version 6.05; San Diego, CA, USA); all $P$-values $\leq 0.05$ were considered statistical significant.

\section{Results}

\section{MCP-1 levels are significantly higher in diabetic pateints} with asthma

T2D is a metabolic disorder involving chronic low-grade systemic inflammation while asthma is a chronic allergic inflammatory disease of the lung. We asked whether the plasma levels of MCP-1/CCL-2, which is a signature inflammatory marker, were elevated in T2D patients with asthma as compared with those having either diabetes or asthma or none of the morbid condition. To this end, as shown in Fig 1, plasma MCP-1 levels were found to be significantly higher in T2D patients with asthma (Group I: $337.95 \pm 46.40 \mathrm{pg} / \mathrm{mL}$ ) as compared with other groups, such as T2D patients without asthma (Group II: 216.69 $\pm 17.30 \mathrm{pg} / \mathrm{mL} ; P=0.03$ ), non-diabetic individuals with asthma (Group III: $251.76 \pm 19.80 \mathrm{pg} / \mathrm{mL} ; P=0.05$ ), and non-diabetic non-asthmatic controls (Group IV: 223.52 $\pm 13.36 \mathrm{pg} / \mathrm{mL} ; P=0.003$ ).

\section{Differential association of plasma MCP-1 levels with markers of inflammation and airway remodeling}

Next, we asked if the plasma MCP-1 levels were associated differentially with various inflammatory and airway remodeling biomarkers in diabetic/non-diabetic individuals with and without asthma. To this effect, our data show (Table 2) that in diabetic patients with asthma, MCP-1 levels correlated with IFN- $\alpha 2$, IL-1RA, IL-10, Fractalkine/CX3CL-1, and VEGF whereas, in diabetic patients without asthma, MCP-1 levels correlated with IL-3, IL-6, IL-9, MIP-1 $\alpha / C C L-3$, MIP-1 $\beta / C C L-4$, GRO$\alpha / C X C L-1$, and BMI. In non-diabetic individuals with asthma, MCP-1 levels correlated with IL-1 $\beta$, IL-1RA, MDC/CCL-22, IP-10/CXCL-10, GM-CSF, FGF-2, PDGF-AA, PDGF-BB, and HbA1c. While, in healthy controls, plasma MCP-1 correlated with IL- $1 \alpha$, IL-1 IL-2, IL-3, IL-9, BMI, FPG, HbA1c, and TG levels. Altogether, MCP-1 associated differentially with the tested inflammatory and pulmonary remodeling biomarkers and was found to correlate positively with: (i) IFN- $\alpha 2$, IL-10, fractalkine, and VEGF in T2D patients with asthma; (ii) IL- 6 and GRO- $\alpha$ in T2D patients without asthma; (iii) MDC, IP-10, GM-CSF, FGF-2, and 


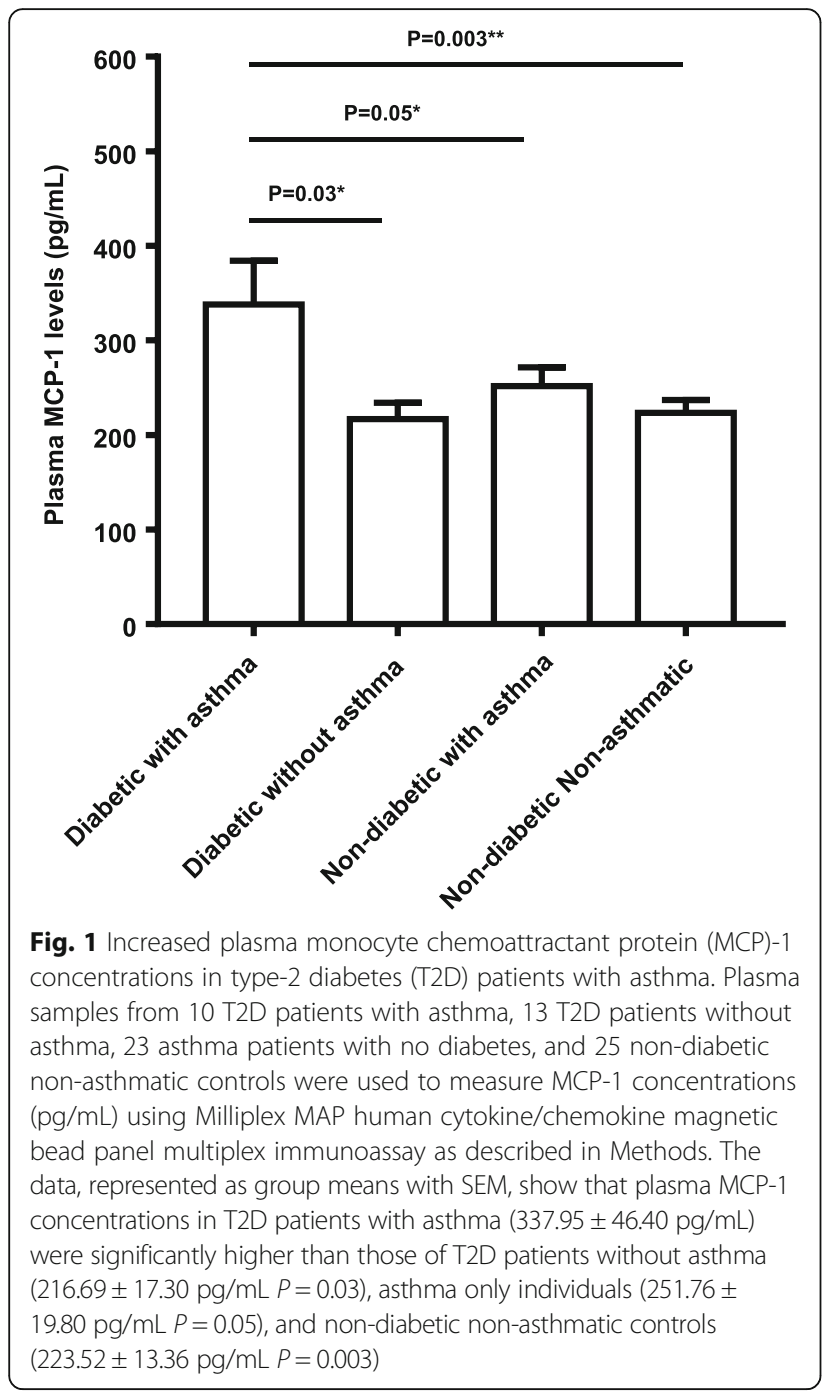

PDGF-AA/BB in patients with asthma only; and (iv) FPG and TG in non-diabetic non-asthmatic controls. Besides, MCP-1 correlated positively with IL-1RA only in asthma patients, irrespective of their diabetes status.

\section{Discussion}

In the present study, significantly elevated plasma MCP1 levels were observed in T2D patients with asthma (Group I) as compared with other groups i.e., individuals with T2D only (Group II, $P=0.03$ ), asthma only (Group III, $P=0.05)$, and non-diabetic non-asthmatic controls (Group IV, $P=0.003$ ). Increased MCP-1 levels have been previously reported in T2D individuals $[8,16]$ as well as in bronchoalveolar lavage fluid from asthmatic patients [17]. Lung is also a target organ for diabetic microangiopathy and the diabetic patients have been reported to be at a higher risk for asthma, chronic obstructive pulmonary disease, pulmonary fibrosis and pneumonia [18]. Mononuclear cells such as lymphocytes and monocytes are involved in systemic and local inflammation in which circulatory monocytes infiltrate into target tissues such as white adipose tissue in case of metabolic inflammation and bronchoalveolar epithelia in asthmatic inflammation. Dandona et al. [13] found the elevated expression of CCR-2 as well as IL-4 and MMP-9 asthma mediators in the mononuclear cell fractions from obese and obese/T2D patients which indicated that these cell populations were responsive to chemotaxis by chemotactic cytokines such as MCP-1/CCL-2 and eotaxin. We speculate that MCP-1 may be a key chemokine involved in monocytic as well as eosinophilic inflammation as both these cell types express cognate CCR-2 receptor. In the present study, MCP-1 levels were found to be significantly higher in diabetic patients with asthma while no significant changes in eotaxin levels could be observed in T2D and/or asthma patients as compared with nondiabetic non-asthmatic controls. It is noteworthy that the presence of asthma in addition to T2D led to a further increase in plasma levels of only the MCP-1 among all biomarkers that we tested in this study which suggests that MCP-1 may be a more sensitive immune marker for disease prognosis in patients inflicted with inflammatory comorbidities, such as T2D and asthma. Hence, the MCP-1 mechanistic link between T2D and asthma may be critical as a risk marker in comorbid inflammatory states. Chemokines play an important role in the pathophysiology of inflammatory diseases including asthma, allergy, atherosclerosis, glomerulonephritis, and obesity/T2D [19]. MCP-1 expression in T2D may be related to the hyperglycemia as high glucose treatment of endothelial cells from diabetic subjects resulted in a $40-70 \%$ increase of MCP-1 and a 10-20\% increase of vascular cell adhesion molecule (VCAM)-1 expression, suggesting a synergistic enhancement due to monocyteendothelial cell interaction [20]. Similarly, another study showed that high glucose concentrations, advanced glycation end products, glycated albumin, and glycoxidized LDL upregulated MCP-1 expression in human endothelial cells [21]. The higher MCP-1 levels that we found in comorbid (asthmatic diabetic) patients may be due to the reason that both disease conditions involve the underlying etiologic factor of chronic inflammation which may become potentiated by a synergistic response between two morbid states. The previous studies have pointed to an increased risk for asthma in obesity [22] and T2D $[18,23]$. We speculate that the obese/T2D individuals with higher systemic and local (broncho-pulmonary epithelial) expression of MCP-1 may be at a high risk and more prone to develop asthma and further studies will be required to verify this line of argument.

In the present study, plasma MCP-1 concentrations were found to be differentially associated with the tested inflammatory, airway remodeling, and allergic biomarkers 
Table 2 Correlation of plasma MCP-1 with immune and clinical biomarkers

\begin{tabular}{|c|c|c|c|c|c|c|c|c|}
\hline \multirow[t]{3}{*}{ Marker } & \multicolumn{4}{|c|}{ Diabetic } & \multicolumn{4}{|c|}{ Non-diabetic } \\
\hline & \multicolumn{2}{|c|}{ Asthmatic } & \multicolumn{2}{|c|}{ Non-asthmatic } & \multicolumn{2}{|c|}{ Asthmatic } & \multicolumn{2}{|c|}{ Non-asthmatic } \\
\hline & $r$ & $P$ & $r$ & $P$ & $r$ & $P$ & $r$ & $P$ \\
\hline IFN-a2 & 0.62 & $0.05^{*}$ & -0.31 & 0.28 & 0.38 & 0.07 & -0.31 & 0.12 \\
\hline $\mathrm{IL}-1 \mathrm{a}$ & -0.37 & 0.46 & 0.28 & 0.64 & 0.18 & 0.53 & -0.57 & $0.01^{*}$ \\
\hline$I L-1 \beta$ & 0.16 & 0.79 & 0.53 & 0.63 & 0.77 & $0.002^{* *}$ & -0.62 & $0.01^{*}$ \\
\hline IL-1RA & 0.65 & $0.03^{*}$ & -0.40 & 0.17 & 0.42 & $0.05^{*}$ & -0.25 & 0.21 \\
\hline $\mathrm{IL}-2$ & -0.40 & 0.43 & -0.76 & 0.07 & 0.51 & 0.07 & -0.49 & $0.03^{*}$ \\
\hline IL-3 & 0.16 & 0.74 & -0.70 & $0.05^{*}$ & -0.17 & 0.57 & -0.78 & $0.0002^{* * *}$ \\
\hline IL-6 & 0.24 & 0.56 & 0.64 & $0.04^{*}$ & 0.39 & 0.11 & -0.11 & 0.62 \\
\hline IL-9 & 0.16 & 0.79 & -0.85 & $0.02 *$ & -0.30 & 0.26 & -0.76 & $0.0004^{* * *}$ \\
\hline IL-10 & 0.70 & $0.02^{*}$ & -0.34 & 0.26 & 0.27 & 0.26 & 0.18 & 0.38 \\
\hline IL-12p70 & 0.22 & 0.52 & -0.48 & 0.09 & 0.27 & 0.23 & -0.26 & 0.20 \\
\hline MDC/CCL-22 & -0.01 & 0.97 & 0.01 & 0.96 & 0.44 & $0.03^{*}$ & 0.37 & 0.07 \\
\hline MIP-1a/CCL-3 & 0.07 & 0.87 & -0.62 & $0.02 *$ & -0.01 & 0.96 & 0.20 & 0.35 \\
\hline MIP-1 $\beta / C C L-4$ & 0.38 & 0.27 & -0.64 & $0.02^{*}$ & 0.15 & 0.48 & -0.19 & 0.40 \\
\hline RANTES/CCL-5 & -0.02 & 0.97 & 0.05 & 0.90 & 0.57 & 0.06 & 0.01 & 0.97 \\
\hline GRO-a/CXCL-1 & 0.47 & 0.16 & 0.54 & $0.05^{*}$ & 0.22 & 0.30 & 0.10 & 0.62 \\
\hline IP-10/CXCL-10 & 0.57 & 0.08 & 0.16 & 0.61 & 0.72 & $<0.0001 * * *$ & 0.18 & 0.37 \\
\hline Fractalkine & 0.70 & $0.02^{*}$ & -0.42 & 0.14 & 0.28 & 0.18 & -0.30 & 0.14 \\
\hline G-CSF & 0.38 & 0.27 & -0.49 & 0.08 & 0.34 & 0.11 & -0.07 & 0.71 \\
\hline GM-CSF & 0.49 & 0.15 & -0.37 & 0.20 & 0.54 & $0.007^{* *}$ & -0.27 & 0.17 \\
\hline FGF-2 & 0.40 & 0.24 & -0.12 & 0.68 & 0.53 & $0.01 *$ & 0.10 & 0.62 \\
\hline PDGF-AA & -0.39 & 0.51 & 0.11 & 0.74 & 0.68 & $0.04^{*}$ & -0.39 & 0.20 \\
\hline PDGF-BB & 0.11 & 0.89 & -0.01 & 0.97 & 0.91 & $0.03^{*}$ & -0.48 & 0.12 \\
\hline VEGF & 0.71 & $0.02^{*}$ & -0.005 & 0.99 & 0.26 & 0.21 & 0.09 & 0.65 \\
\hline FLT-3 L & -0.30 & 0.55 & -0.61 & 0.07 & 0.01 & 0.99 & -0.16 & 0.50 \\
\hline $\lg E$ & 0.61 & 0.06 & -0.39 & 0.38 & 0.25 & 0.26 & 0.19 & 0.57 \\
\hline $\mathrm{BMI}\left(\mathrm{kg} / \mathrm{m}^{2}\right)$ & -0.19 & 0.59 & -0.54 & $0.05^{*}$ & 0.18 & 0.39 & 0.40 & $0.04^{*}$ \\
\hline FPG (mmol/L) & -0.11 & 0.74 & 0.20 & 0.51 & 0.40 & 0.06 & 0.46 & $0.02^{*}$ \\
\hline HbA1c (\%) & 0.03 & 0.93 & -0.24 & 0.42 & 0.47 & $0.02^{*}$ & 0.40 & $0.05^{*}$ \\
\hline $\mathrm{TG}(\mathrm{mmol} / \mathrm{L})$ & 0.25 & 0.47 & -0.12 & 0.68 & 0.21 & 0.31 & 0.48 & $0.01 *$ \\
\hline
\end{tabular}

IFN Interferon, IL interleukin, CCL CC chemokine ligand, CXCL CXC chemokine ligand, MDC macrophage derived chemokine, MIP macrophage inflammatory protein, RANTES regulated on activation, normal T-cell expressed and secreted, GRO growth regulated oncogene, IP IFN- $\gamma$-inducible protein, G-CSF granulocyte colony-stimulating factor, GM-CSF granulocyte-macrophage colony-stimulating factor, FGF fibroblast growth factor, PDGF platelet derived growth factor, VEGF vascular endothelial growth factor, FLT-3 L FMS-like tyrosine kinase 3 ligand, IgE immunoglobulin E

All statistical values are indicated in boldface

*significant, **highly significant, ${ }^{* * *}$ extremely significant

in diabetic/non-diabetic individuals, with and without asthma. Thus, plasma MCP-1 levels correlated positively with those of: (i) IFN- $\alpha 2$, IL-10, fractalkine, and VEGF in T2D patients with asthma; (ii) IL- 6 and GRO- $\alpha$ in T2D patients without asthma; (iii) MDC, IP-10, GM-CSF, FGF2 , and PDGF-AA/BB in asthma only patients; and (iv) FPG and TG in non-diabetic non-asthmatic individuals. This association of MCP-1 with all these biomarkers points to a complex interplay of multiple proteins that leads to the etiopathogenesis of $\mathrm{T} 2 \mathrm{D}$ and/or asthma.
Notably, the MCP-1 link with both fractalkine and VEGF in T2D patients with asthma reflects its significance as a risk marker in morbid conditions with complex immunologic phenotype of inflammation and angiogenesis. The relationship of MCP-1 with more than one growth factors including GM-CSF, FGF-2, and PDGF as we detected in asthma only patients is in agreement, at least in part, with previous reports showing that FGF-2/PDGF and GM-CSF were detected and important as remodeling and susceptibility biomarkers, respectively, for allergic asthma [24-26]. 
In contrast to the study reporting a positive correlation between MCP-1 gene expression and BMI in obesity/T2D [27], we did not find a positive association between plasma MCP-1 levels and obesity/T2D clinical markers such as BMI, FPG, HbA1c, and TG in our diabetic cohort. In agreement with our results, Herder et al. reported data from 236 T2D patients, 242 subjects with impaired glucose tolerance, and 244 normoglycemic controls indicating that the MCP-1 levels were not associated with impaired glucose tolerance, T2D or several parameters of obesity [28]. Our data further show that in asthma patients, irrespective of their T2D status, MCP-1 associated positively also with IL-1RA which is an important indicator of the anti-inflammatory competency of these individuals while the IL-1 $\beta /$ IL-1RA balance plays a key role in asthmatic inflammation. The IgE-mediated stimulation of mast cells has been shown to induce IL-1RA expression [29]. Interestingly, in our study, MCP-1 also showed a positive association with IgE levels $(r=0.61)$ in diabetic individuals with asthma; however, it did not approach the level of significance $(P=0.06)$. Overall, our data indicate that plasma MCP-1 levels associate selectively with a wide range of inflammatory cytokines/chemokines, growth/activation factors and could, therefore, be important as a biomarker for asthma in diabetic and non-diabetic subjects while this association of plasma MCP-1 with asthma appears to be driven by the conventional risk factors for inflammation and pulmonary tissue remodeling.

\section{Conclusion}

In summary, our data show that plasma MCP-1 levels were significantly elevated in T2D patients with asthma as compared with those without asthma, and these changes in the systemic MCP-1 related differentially with important biomarkers of inflammation and airway remodeling. Nonetheless, further studies involving larger study cohorts as well as other parameters which might affect inflammation but were not addressed in our study, such as drug therapy will be required to understand the functional significance of MCP-1 in asthma.

\footnotetext{
Abbreviations

BMI: Body mass index; CCL: CC chemokine ligand; CXCL: CXC chemokine ligand; ECP: Eosinophil cationic protein; EGF: Epidermal growth factor; ELISA: Enzyme-linked immunosorbent assay; FEV $\mathrm{F}_{1}$ : Forced expiratory volume in $1 \mathrm{sec}$; FGF: Fibroblast growth factor; FLT-3 L: FMS-like tyrosine kinase 3 ligand; FPG: Fasting plasma glucose; G-CSF: Granulocyte colony-stimulating factor; GM-CSF: Granulocyte-macrophage colony-stimulating factor; GRO: Growth regulated oncogene; HbA1c: Glycated hemoglobin; HDL: Highdensity lipoprotein; IFN: Interferon; IgE: Immunoglobulin E; IL: Interleukin; IL1RA: IL-1 receptor agonist; IP: IFN- $\gamma$-inducible protein; LDL: Low-density lipoprotein; MCP-1: Macrophage chemoattractant protein-1; MDC: Macrophage derived chemokine; MIP: Macrophage inflammatory protein; OGTT: Oral glucose tolerance test; PDGF: Platelet-derived growth factor; RANTES: Regulated on activation, normal T-cell expressed and secreted; sCD40L: soluble CD40 ligand; T2D: Type-2 diabetes; TG: Triglycerides; TGF: Transforming growth factor; VCAM-1: Vascular cell adhesion molecule-1; VEGF: Vascular endothelial growth factor
}

\section{Acknowledgments}

We thanks all our participants for their voluntary participation, cooperation, and support.

\section{Availability of data and materials \\ Not applicable.}

\section{Funding}

This study was supported by Kuwait Foundation for Advancement of Sciences (KFAS) (Grant \#: RA-2011-015).

\section{Authors' contributions}

SS analyzed the data and wrote the manuscript. MK, AA and NA performed experiments. SZ and SA recruited the study subjects and obtained clinical data of the subjects. SD performed statistical analysis. RA conceived, designed the experiments, wrote and edited the manuscript. All authors read and approved the final manuscript.

\section{Competing interests}

The authors declare that they have no competing interests.

\section{Ethics approval and consent to participate}

Written informed consent was obtained from all participants before enrolment in the study and the study protocol was approved by Ethical Review Committee of Dasman Diabetes Institute, Kuwait.

\section{Author details}

${ }^{1}$ Immunology \& Innovative Cell Therapy Unit, P.O. Box 1180, Dasman 15462 , Kuwait. ${ }^{2}$ Tissue Bank Facility, Dasman Diabetes Institute (DDI), P.O. Box 1180, Dasman 15462, Kuwait.

Received: 25 May 2016 Accepted: 22 September 2016

Published online: 29 September 2016

\section{References}

1. Donath MY. Targeting inflammation in the treatment of type 2 diabetes: time to start. Nat Rev Drug Disc. 2014;13(6):465-76.

2. Sjoholm A, Nystrom T. Inflammation and the etiology of type 2 diabetes. Diab Metab Res Rev. 2006;22(1):4-10.

3. Cefalu WT. Inflammation, insulin resistance, and type 2 diabetes: back to the future? Diabetes. 2009;58(2):307-8.

4. Murdoch JR, Lloyd CM. Chronic inflammation and asthma. Mutat Res. 2010; 690(1-2):24-39.

5. Barnes PJ. The cytokine network in asthma and chronic obstructive pulmonary disease. J Clin Invest. 2008;118(11):3546-56.

6. Weisberg SP, McCann D, Desai M, Rosenbaum M, Leibel RL, Ferrante Jr AW. Obesity is associated with macrophage accumulation in adipose tissue. J Clin Invest. 2003;112(12):1796-808.

7. Tsou CL, Peters W, Si Y, Slaymaker S, Aslanian AM, Weisberg SP, et al. Critical roles for CCR2 and MCP-3 in monocyte mobilization from bone marrow and recruitment to inflammatory sites. J Clin Invest. 2007;117(4):902-9.

8. Harsimran K, Singh AA, Guruvinder S, Sharda S, Vasudha S. Plasma monocyte chemoattractant protein-1 as risk marker in type 2 diabetes mellitus and coronary artery disease in North Indians. Diab Vasc Dis Res. 2009;6(4):288-90.

9. Yoshimura T, Robinson EA, Tanaka S, Appella E, Leonard EJ. Purification and amino acid analysis of two human monocyte chemoattractants produced by phytohemagglutinin-stimulated human blood mononuclear leukocytes. J Immunol. 1989;142(6):1956-62.

10. Lawlor DA, Ebrahim S, Smith GD. Associations of measures of lung function with insulin resistance and Type 2 diabetes: findings from the British Women's Heart and Health Study. Diabetologia. 2004;47(2):195-203.

11. Davis WA, Knuiman M, Kendall P, Grange V, Davis TM. Fremantle Diabetes S. Glycemic exposure is associated with reduced pulmonary function in type 2 diabetes: the Fremantle Diabetes Study. Diab care. 2004;27(3):752-7.

12. Beuther DA, Sutherland ER. Overweight, obesity, and incident asthma: a meta-analysis of prospective epidemiologic studies. Am J Resp Crit Care Med. 2007;175(7):661-6.

13. Dandona P, Ghanim H, Monte SV, Caruana JA, Green K, Abuaysheh S, et al. Increase in the mediators of asthma in obesity and obesity with type 2 diabetes: reduction with weight loss. Obesity. 2014;22(2):356-62. 
14. Nathan C. Epidemic inflammation: pondering obesity. Mol Med. 2008; 14(7-8):485-92

15. Miller MR, Hankinson J, Brusasco V, Burgos F, Casaburi R, Coates A, et al. Standardisation of spirometry. Eur Respir J. 2005;26(2):319-38.

16. Piemonti L, Calori G, Mercalli A, Lattuada G, Monti P, Garancini MP, et al. Fasting plasma leptin, tumor necrosis factor-alpha receptor 2 , and monocyte chemoattracting protein 1 concentration in a population of glucose-tolerant and glucose-intolerant women: impact on cardiovascular mortality. Diab care. 2003;26(10):2883-9.

17. Holgate ST, Bodey KS, Janezic A, Frew AJ, Kaplan AP, Teran LM. Release of RANTES, MIP-1 alpha, and MCP-1 into asthmatic airways following endobronchial allergen challenge. Am J Respir Crit Care Med. 1997;156(5): 1377-83.

18. Ehrlich SF, Quesenberry Jr CP, Van Den Eeden SK, Shan J, Ferrara A. Patients diagnosed with diabetes are at increased risk for asthma, chronic obstructive pulmonary disease, pulmonary fibrosis, and pneumonia but not lung cancer. Diab care. 2010;33(1):55-60.

19. Szalai C, Kozma GT, Nagy A, Bojszko A, Krikovszky D, Szabo T, et al. Polymorphism in the gene regulatory region of $\mathrm{MCP}-1$ is associated with asthma susceptibility and severity. J Allergy Clin Immunol. 2001;108(3):375-81.

20. Panee J. Monocyte Chemoattractant Protein 1 (MCP-1) in obesity and diabetes. Cytokine. 2012;60(1):1-12.

21. Ihm CG, Park JK, Hong SP, Lee TW, Cho BS, Kim MJ, et al. A high glucose concentration stimulates the expression of monocyte chemotactic peptide 1 in human mesangial cells. Nephron. 1998;79(1):33-7.

22. Ford ES. The epidemiology of obesity and asthma. J Allergy Clin Immunol. 2005;115(5):897-909.

23. Thomsen SF, Duffy DL, Kyvik KO, Skytthe A, Backer V. Risk of asthma in adult twins with type 2 diabetes and increased body mass index. Allergy. 2011; 66(4):562-8.

24. Bissonnette EY, Madore AM, Chakir J, Laviolette M, Boulet LP, Hamid Q, et al. Fibroblast growth factor-2 is a sputum remodeling biomarker of severe asthma. J Asthma. 2014;51(2):119-26.

25. Lewis CC, Chu HW, Westcott JY, Tucker A, Langmack EL, Sutherland ER, et al. Airway fibroblasts exhibit a synthetic phenotype in severe asthma. J Allergy Clin Immunol. 2005;115(3):534-40.

26. Llop-Guevara A, Chu DK, Walker TD, Goncharova S, Fattouh R, Silver JS, et al. A GM-CSF/L-33 pathway facilitates allergic airway responses to subthreshold house dust mite exposure. PLoS One. 2014;9(2):e88714.

27. Chacon MR, Fernandez-Real JM, Richart C, Megia A, Gomez JM, Miranda M, et al. Monocyte chemoattractant protein-1 in obesity and type 2 diabetes. Insulin sensitivity study. Obesity. 2007;15(3):664-72.

28. Herder C, Muller-Scholze S, Rating P, Koenig W, Thorand B, Haastert B, et al. Systemic monocyte chemoattractant protein-1 concentrations are independent of type 2 diabetes or parameters of obesity: results from the Cooperative Health Research in the Region of Augsburg Survey S4 (KORA S4). Eur J Endocrinol/Eur Feder Endocr Soc. 2006;154(2):311-7.

29. Hagaman DD, Okayama Y, D'Ambrosio C, Prussin C, Gilfillan AM, Metcalfe DD. Secretion of interleukin-1 receptor antagonist from human mast cells after immunoglobulin E-mediated activation and after segmental antigen challenge. Am J Respir Cell Mol Biol. 2001;25(6):685-91.

\section{Submit your next manuscript to BioMed Central and we will help you at every step:}

- We accept pre-submission inquiries

- Our selector tool helps you to find the most relevant journal

- We provide round the clock customer support

- Convenient online submission

- Thorough peer review

- Inclusion in PubMed and all major indexing services

- Maximum visibility for your research

Submit your manuscript at www.biomedcentral.com/submit
Biomed Central 